\title{
An Allee Effect Reduces the Invasive Potential of Tilletia indica
}

\author{
K. A. Garrett and R. L. Bowden
}

First author: Department of Plant Pathology, 4024 Throckmorton Plant Sciences Center, Kansas State University, Manhattan 66506; and second author: U.S. Department of Agriculture-Agricultural Research Service, Plant Science and Entomology Research Unit, 4007 Throckmorton Plant Sciences Center, Kansas State University, Manhattan 66506.

Accepted for publication 20 July 2002.

\begin{abstract}
Garrett, K. A., and Bowden, R. L. 2002. An Allee effect reduces the invasive potential of Tilletia indica. Phytopathology 92:1152-1159.

The Karnal bunt pathogen, Tilletia indica, is heterothallic and depends on encounters on wheat spikes between airborne secondary sporidia of different mating types for successful infection and reproduction. This life history characteristic results in reduced reproductive success for lower population densities. Such destabilizing density dependence at low population levels has been described for a range of animals and plants and is often termed an Allee effect. Our objective was to characterize how the Allee effect might reduce the invasive potential of this economically important pathogen. We developed a simple population model of $T$. indica that incorporates an Allee effect by calculating the probability of infection for different numbers of secondary sporidia in the infection court. An
\end{abstract}

ABSTRACT
Allee effect is predicted to be important at the frontier of an invasion, for establishment of new foci by a small population of teliospores, and when the environment is nonconducive for the production of secondary sporidia. Using estimated model parameter values, we demonstrated a theoretical threshold population size below which populations of $T$. indica were predicted to decline rather than increase. This threshold will vary from season to season as a function of weather variables and their effect on the reproductive potential of $T$. indica. Deployment of partial resistance or use of fungicides may be more useful if they push population levels below this threshold.

Additional keywords: depensation, invasive species, minimum viable population, partial bunt, spore bank, threshold criteria.
Tilletia indica Mitra causes Karnal bunt of bread wheat, durum wheat, and triticale (17) and can infect a number of other grass species (40). Although disease incidence and yield losses in wheat are typically very low, it can impart an unpleasant odor to flour when incidence exceeds $3 \%(4,17,28,35)$. Numerous wheatimporting countries have quarantines against the import of wheat with Karnal bunt, so the presence of Karnal bunt in a region can seriously affect international grain trade $(4,17,47)$.

The worldwide distribution of T. indica is limited (41). It was first found in 1930 at Karnal, Haryana, in northern India (34). It has since been reported from Pakistan, Afghanistan, Iran, Iraq, Syria, Nepal, and Mexico $(4,17,35)$. It was first detected in the United States in 1996 in Arizona and one adjacent county in California (53). In 1997, it was detected in one county in central Texas. In 2001, it was detected in an additional county in central Texas and four counties in northern Texas. In the same year, it was reported from South Africa (6).

Detection of $T$. indica in new areas has renewed concerns that the pathogen might soon invade other wheat-producing regions in the United States and elsewhere (46,47). However, the spread of T. indica in Mexico from 1970 to 1996 was relatively slow (18). Circumstantial evidence suggests that it has often been introduced into new areas without successful establishment (1). Several factors might contribute to the apparent low rate of establishment and spread. First, $T$. indica has relatively narrow environmental requirements that may limit its success $(1,27,36)$. Another possibility is that introduced population sizes may often be below the minimum required for a significant probability of successful infection, as

Corresponding author: K. A. Garrett; E-mail address: kgarrett@ksu.edu

Publication no. P-2002-0926-010

(c) 2002 The American Phytopathological Society suggested for dwarf bunt (22). A third factor is the unusual life history characteristics of $T$. indica that may influence its potential as an invasive species.

The life cycle of $T$. indica differs from those of other bunt diseases of wheat in several ways (41). Teliospores of T. controversa, $T$. laevis, and T. tritici germinate and produce haploid primary sporidia (basidiospores) that conjugate immediately on the promycelium and then produce dikaryotic infectious hyphae or dikaryotic secondary sporidia that systemically infect seedling plants. In contrast, teliospores of $T$. indica germinate and produce monokaryotic, haploid, primary sporidia that do not conjugate, but rather germinate and produce numerous monokaryotic, haploid, secondary sporidia. The secondary sporidia are airborne to plant surfaces where they may germinate and produce additional generations of secondary sporidia $(2,10,35)$. Wheat spikes are susceptible from early head emergence through late anthesis $(4,17$, $30,35,39,51)$. Secondary sporidia that arrive on host florets during the interval of susceptibility germinate and penetrate through stomates on glumes, lemmas, paleas (21), and possibly the rachis $(8,21,38)$. We will refer to this stage of infection as monokaryon infection.

T. indica is heterothallic and has four known bipolar mating types $(12,16)$. Dikaryotization and pathogenesis can only occur when individuals of two different mating types anastomose. Unlike many other bunt and smut fungi, anastomosis does not occur readily in vitro (12) and anastomosis was only rarely observed on floral surfaces (21). Therefore, anastomosis probably occurs inside the host tissue and results in what we will refer to as dikaryon infection. Dikaryon infections may be localized to one floret or there may be some limited spread between adjacent florets within a spikelet or between adjacent spikelets within a spike $(9,38,44)$. Dikaryotic hyphae penetrate the pericarp through the funiculus and eventually form monokaryotic, diploid teliospores $(19,21)$. 
Teliospores are released from infected grain during harvest and can remain viable in the soil for several years $(17,35)$.

The obligate sexual cycle, airborne dispersal of haploid propagules, and generally low incidence of $T$. indica imply that it will experience an Allee effect (49). An Allee effect (also known as depensation) is a disproportionate reduction in reproductive success at low population densities. Allee effects are often due to the increased difficulty of finding a mate, but several other mechanisms have been described (33). Allee effects have been studied extensively in conservation biology where small populations may have an increased risk of extinction due to an Allee effect $(24,42,48)$. Similarly, the concept has been incorporated in devising optimal strategies for introducing self-sustaining populations of biocontrol agents (23). An Allee effect also has significant implications for invasive species such as exotic animals, plants, or pathogens $(29,32)$. An Allee effect can alter the probability of extinction, increase population thresholds for establishment, and explain accelerating rates of invasion as well as the shape of an invasion wave (7).

An Allee effect could be important for understanding the epidemiology of $T$. indica and developing management strategies for Karnal bunt. Our first objective in this work is to estimate how density-dependent reproduction limits infection by secondary sporidia of T. indica. Second, we consider the implications of an Allee effect on numerical thresholds for population growth, including the case of populations initiated by teliospores transported into new areas. Third, we investigate how the Allee effect might influence population changes over a period of years. Through these models we also focus attention on which points in the life cycle of $T$. indica are in need of greater research in order to understand the risk of invasion by this pathogen.

\section{MODEL AND PREDICTIONS}

Our model of reproduction for T. indica is constructed in three parts. First, we estimate the probability of successful dikaryon infection as a function of the density of monokaryon infections using the Poisson distribution. Second, we incorporate this densitydependent step into a model of the life cycle of $T$. indica to consider its effect within the context of a complete season. Third, we incorporate a fluctuating environment and the soilborne teliospore bank to illustrate the potential impact of an Allee effect over multiple seasons.

Estimation of the Allee effect. $T$. indica produces both filiform and allantoid secondary sporidia (10,41). Only allantoid secondary sporidia are forcibly discharged and they were the only type found in the field on sticky tape spore traps (2). Dhaliwal and Singh (10) considered them to be the only important infective propagules of T. indica. They may be produced at the soil level, on the leaves, or on spikes $(2,4,10,41)$. Nagarajan et al. (35) envisioned multiple cycles of reproduction and migration up the canopy layers of the host, a phenomenon they called "monkey jumping". We will assume that the origin of airborne allantoid secondary sporidia is not critical and that they can be treated as one population for modeling purposes.

The Allee effect comes into play when an allantoid secondary sporidium reaches an infection court (floret) and must encounter another individual of a different mating type for dikaryotization and successful reproduction. In developing our model, we will assume that secondary sporidia are randomly and independently distributed over the infection courts in a given small area. We also assume that the environment in the area under consideration is homogeneous with regard to conduciveness to infection. We do not explicitly model secondary spread between florets, but it could easily be accommodated (Table 1 , parameter $r_{5}$ ).

A proportion of secondary sporidia in the infection court will successfully form monokaryon infections (21). For high densities of monokaryon infections, the rate of success in producing di- karyon infections may be reduced due to limited host tissue availability. For low densities, it may be reduced due to limited availability of mates. The following model incorporates both of these forms of density-dependent reproduction.

Under our assumptions, the number of monokaryon infections in a given floret follows a Poisson distribution (13) with mean $\lambda$, the mean number of monokaryon infections per floret. Similar reasoning has been used to estimate Allee effects for animals (reviewed in literature citation 33). For T. indica, multiple mating types must be incorporated into the model. Suppose that there are $n$ mating types, and that each mating type represents the same proportion of the population of secondary sporidia. Then, the probability of exactly $x$ monokaryon infections of a particular mating type in a given floret will also follow a Poisson distribution, but with mean $\lambda / n$. The probability distribution $P_{X}(x)$ for the number $(x)$ of monokaryon infections of a given mating type at a floret is then the same for each mating type and is

$$
P_{X}(x)=e^{-\lambda / n}(\lambda / n)^{x} / x !
$$

(These means could be adjusted accordingly if the proportions of different mating types were not equal.) The probability that at least one secondary sporidium of a given mating type will infect a given floret is

$$
1-P_{X}(0)=1-e^{-\lambda / n}
$$

The probability that at least one monokaryon infection (MI) of each of at least two different mating types will be present in a given floret, thus making dikaryon infection of that floret possible, is

$$
\begin{aligned}
P^{*}= & 1-\operatorname{Prob}(\text { no mating type has } \geq 1 \mathrm{MI}) \\
& - \text { Prob(only } 1 \text { mating type has } \geq 1 \mathrm{MI}) \\
= & 1-\operatorname{Prob}(\text { a mating type has } 0 \mathrm{MI})^{n} \\
& \left.-n \text { Prob(a mating type has } 0 \mathrm{MI})^{n-1} \text { Prob(a mating type has } \geq 1 \mathrm{MI}\right) \\
= & 1-\left(e^{-\lambda / n}\right)^{n}-n\left(e^{-\lambda / n}\right)^{n-1}[1-\operatorname{Prob}(\text { a mating type has } 0 \mathrm{MI})] \\
= & 1-e^{-\lambda}-n e^{-(n-1) \lambda / n}\left(1-e^{-\lambda / n}\right)
\end{aligned}
$$

We are assuming that monokaryon infections in the same infection court (floret) will encounter each other and form dikaryons. Goates (21) showed that hyphae colonizing the lemma, palea, or glume grow toward the bottom of the floret where they may meet at the floret base or in the subovarian tissue. If it were necessary to take into account the spatial arrangement of monokaryon infections in the infection court, a Rayleigh distribution could be adapted to model the distribution of the distance from a given monokaryon infection to its nearest neighbor (13). This additional density dependence would increase the Allee effect.

We use equations 3 (with $n=4$ ) and 2 (with $n=1$ ) to compare the expected proportion of infected florets with and without the Allee effect, respectively (Fig. 1A). The first case represents Karnal bunt caused by $T$. indica. The latter case represents a disease for which propagules are not constrained to find a mate; under conducive conditions, a single propagule can initiate an infection. At this point, we assume that all dikaryon infections are successful.

Comparing the model predictions with and without the Allee effect, there is a threefold difference in the proportion of successful infections at a density of $\lambda=1.0$ monokaryon infection per floret (Fig. 1A). The relative difference between infection rates increases as the propagule density decreases. At a density of $\lambda=$ 0.1 monokaryon infections per floret, there is a 27 -fold difference. The absolute difference between the proportions of florets infected is greatest for monokaryon densities around one per floret. At densities above seven per floret, the predictions converge and the availability of uninfected florets is limiting.

Invasion of new sites via secondary sporidia. Long-distance movement of sporidia has been mentioned as a potential mecha- 
nism for initiating populations of $T$. indica in new regions (1, 45). Under the assumptions of our model, $T$. indica experiences disproportionately decreasing reproductive success as sporidial density decreases with distance from a source. The number of dikaryon infections per monokaryon infection can be obtained by dividing equations 2 or 3 by $\lambda$ (Fig. 1B). At some distance from the source, the density-dependent probability of successful infection per propagule approaches zero for $T$. indica. In contrast, the density-dependent probability of successful infection per propagule would approach one for an organism with no Allee effect, assuming as we are at this point that all dikaryon infections are successful.

The difference between the response with and without the Allee effect will be reflected in the difference between disease gradients and dispersal gradients for $T$. indica. Unfortunately, estimates of propagule dispersal on the many scales of interest for determining invasion risks for Karnal bunt are not available. Typical data sets for other pathogens provide estimates of dilution of propagules over distances such as $10 \mathrm{~m}$. Over such a small distance, reductions in the density of successful propagules of 1 order of magnitude have been observed for Gibberella zeae $(15,37)$. Although it is important to use caution when extrapolating from such models over larger distances, it seems reasonable to assume, for example, that the dilution in propagule density over $1,000 \mathrm{~m}$ would be at least 3 orders of magnitude. If we take the case where $\lambda$ is 0.1 at the inoculum source, then at a distance of $1,000 \mathrm{~m}, \lambda$ would be less than or equal to 0.0001 and the proportion infected would be less than or equal to $10^{-9}$. The difference in expected infection rates with or without the Allee effect would be at least 4 orders of magnitude (Fig. 1). When the dispersal gradient for secondary sporidia of $T$. indica is better known, it can be used in combination with a model of the Allee effect to estimate the effective dispersal distance of secondary sporidia.

Demographic model over a single year. In order to consider how density-dependent reproduction at low population levels may influence growth of $T$. indica populations, we constructed a simple difference equation model to describe the changes in the $T$. indica population over a year. We defined the parameters that determine the progress of $T$. indica populations in order to characterize the relevant parameter space and clarify where more information is needed to construct risk assessments for T. indica (Table 1). For the sake of simplicity, we do not take into account emigration or immigration. We developed two versions of the model, with and without the Allee effect at the point where secondary sporidia must encounter each other in florets. We begin with the simpler version.

First, the number of monokaryon infections in an area in year $t$ $\left(M_{t}\right)$ is a function of the number of viable teliospores at the beginning of the season $\left(T_{t}\right)$ :

$$
M_{t}=r_{1} r_{2} r_{3} T_{t}
$$

where $r_{1}$ and $r_{2}$ are the rates of production of primary and secondary sporidia, respectively (Table 1 ), and $r_{3}$ is the proportion of secondary sporidia that retain viability and reach the infection court of a susceptible host during the interval of susceptibility to produce a monokaryon infection. Second, the number of florets with dikaryon infections in an area in generation $t\left(F_{t}\right)$ is

TABLE 1. Parameters describing demographics of Tilletia indica

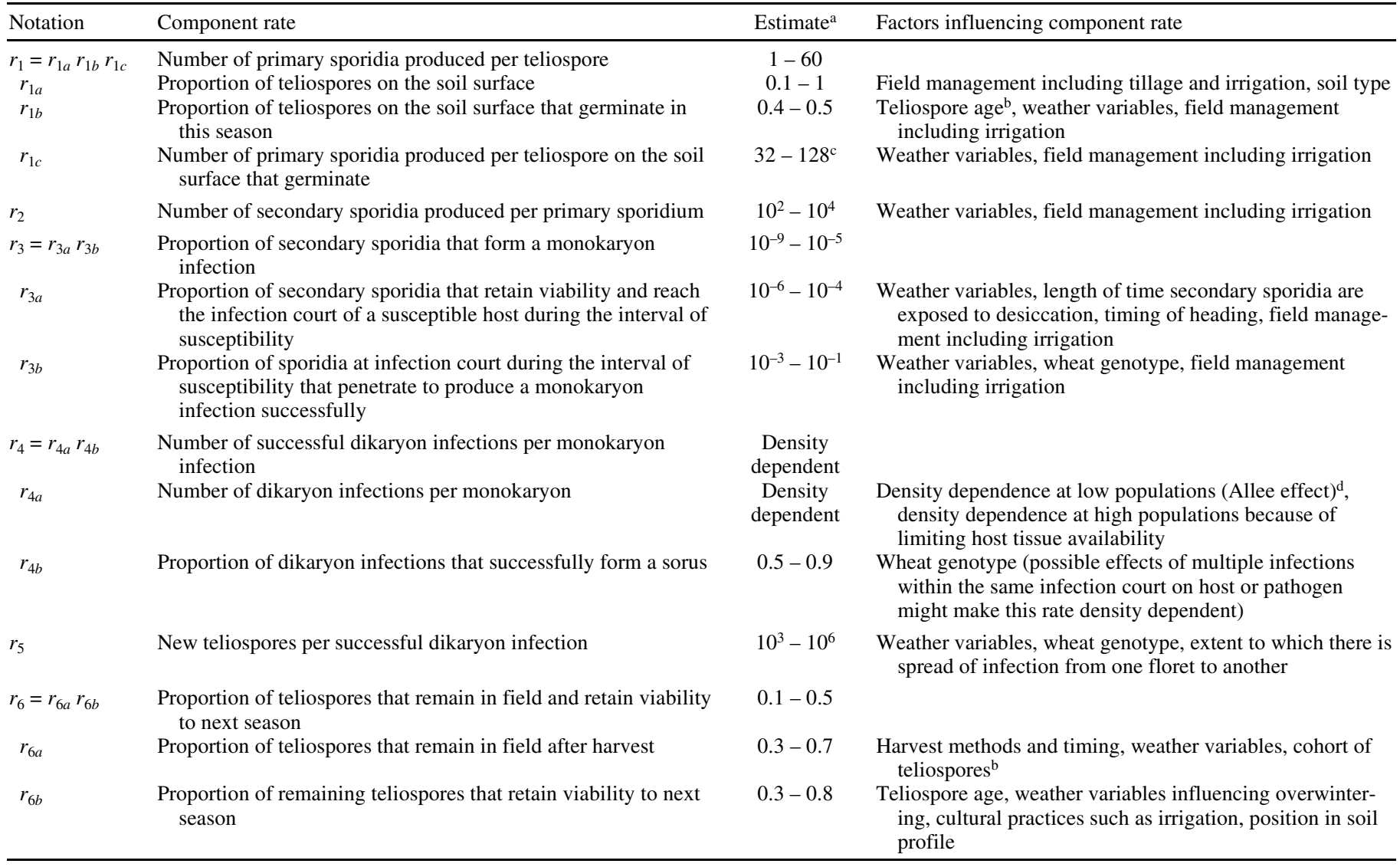

a Estimates are based on conversations with several Karnal bunt researchers and represent likely rates when epidemics are occurring.

${ }^{\mathrm{b}}$ A more detailed model could include teliospore age class cohorts.

${ }^{\mathrm{c}}$ Estimate from Fuentes-Dávila (17).

${ }^{\mathrm{d}}$ In equation 8 we model a scenario in which reproduction is density dependent at low populations because at least two mating types must be present in the infection court, assuming that individuals within the infection court will encounter each other. To whatever extent individuals within an infection court may not all encounter each other, $r_{4 b}$ will be further reduced as populations become smaller. 
a function of the number of monokaryon infections present at that time $\left(M_{t}\right)$ :

$$
F_{t}=r_{4} M_{t}
$$

where $r_{4}$ is the number of dikaryon infections per monokaryon infection. Since we are not yet incorporating density-dependent constraints on dikaryon infection, we momentarily treat $r_{4}$ as equal to 1. Third, the number of viable teliospores in an area at the end of season $t\left(T_{t+1}\right)$ is a function of the number of florets with dikaryon infection $\left(F_{t}\right)$ that can produce new teliospores and the rate of teliospore survival:

$$
T_{t+1}=r_{5} r_{6} F_{t}
$$

where $r_{5}$ is the number of teliospores produced per floret with dikaryon infection and $r_{6}$ is the proportion of teliospores that remain after harvest and retain viability to the next season. The different steps of this model for a single season (not yet including density-dependent effects) can be summarized by

$$
T_{t+1}=r_{1} r_{2} r_{3} r_{4} r_{5} r_{6} T_{t}
$$

In this model, each of these component rates (Table 1, $r_{1}$ through $r_{6}$ ) will have a similar influence on epidemic progress. If one of the component rates is very low or very high, this may be counterbalanced by the other rates. As long as the product $r_{1} r_{2} r_{3} r_{4} r_{5} r_{6}$ is at least one, the population will be maintained. When we incorporate the Allee effect, it becomes clear that the early season reproductive rate $\left(r_{1} r_{2} r_{3}\right)$ is particularly important in a single season because it determines how large the population of monokaryon infections will be when the density-dependent stage of the life cycle is reached. Referring to equation 3 ,

$$
\begin{aligned}
F_{t} & =H P_{t}^{*}=H\left[1-e^{-\lambda t}-n e^{-(n-1) \lambda t / n}\left(1-e^{-\lambda t / n}\right)\right] \\
& =H\left(1-\exp \left(-M_{t} / H\right)-n \exp \left[-(n-1) M_{t} /(H n)\right]\left\{1-\exp \left[-M_{t} /(H n)\right]\right\}\right)
\end{aligned}
$$

where $\lambda_{t}$ may vary from one season to another and $H$ is the total number of florets in the area under consideration. If we consider an area of approximately $1 \mathrm{~m}^{2}$, there would be on the order of $H=$ 20,000 florets. Using equation 8 , we derive an equation analogous to equation 7 , but incorporating the Allee effect.

$$
\begin{aligned}
T_{t+1}= & r_{4 b} r_{5} r_{6} H\left(1-\exp \left(-r_{1} r_{2} r_{3} T_{t} / H\right)\right. \\
& \left.-n \exp \left[-(n-1) r_{1} r_{2} r_{3} T_{t} /(H n)\right]\left\{1-\exp \left[-r_{1} r_{2} r_{3} T_{t} /(H n)\right]\right\}\right)
\end{aligned}
$$

By comparison, if each sporidium were capable of independently producing a dikaryon infection, the formula would be constructed using equation 2 as

$$
T_{t+1}=r_{4 b} r_{5} r_{6} H\left[1-\exp \left(-r_{1} r_{2} r_{3} T_{t} / H\right)\right]
$$

Invasion of new sites via teliospores. Teliospores of $T$. indica may be disseminated by a variety of pathways including contaminated seed, updrafts from burning fields, vehicles, and animals $(4,47)$. Establishment of a new population of $T$. indica via teliospores is probably easier than via windblown secondary sporidia because, under conducive conditions, a small number of teliospores is capable of producing a large number of secondary sporidia in a concentrated area and the frequency of different mating types is more likely to be balanced. Still, for any given values of the density-independent reproductive rates (the product $\left.\begin{array}{llllll}r_{1} & r_{2} & r_{3} & r_{4 b} & r_{5} & \left.r_{6}\right)\end{array}\right)$ that are not too high, a teliospore threshold for establishment in a given area will exist, with or without the Allee effect (Fig. 2A and B).

Using our parameter estimates, the Allee effect raises the teliospore threshold for establishment by approximately 2 orders of magnitude. Although the magnitude depends on the parameter values, the direction of change is consistent. Therefore, the Allee effect can substantially reduce the ability of $T$. indica to establish new disease foci from small populations of teliospores.

Behavior of the thresholds is very dependent on early season reproductive rates. For example, consider the predicted responses in Figure 2, based on equations 9 and 10. There is a large region (Region 1), especially for lower reproductive rates, in which the model prediction asserts that less than one dikaryon infection will occur in the area of interest. This region is much larger when the Allee effect is included in the model. The boundary line (threshold) above this region represents the combination of initial number of viable teliospores and early season reproductive rate $\left(\begin{array}{lll}r_{1} & r_{2} & r_{3}\end{array}\right)$ for which a single dikaryon infection is predicted. The region in which at least one dikaryon infection is predicted is also split into two regions. For lower early season reproductive rates, even though more than one dikaryon infection is predicted, there is not sufficient teliospore production to replace the number of teliospores lost over the course of the year. For higher reproductive rates, there is a net gain in the number of teliospores. Early season reproductive rates are most important because they determine the
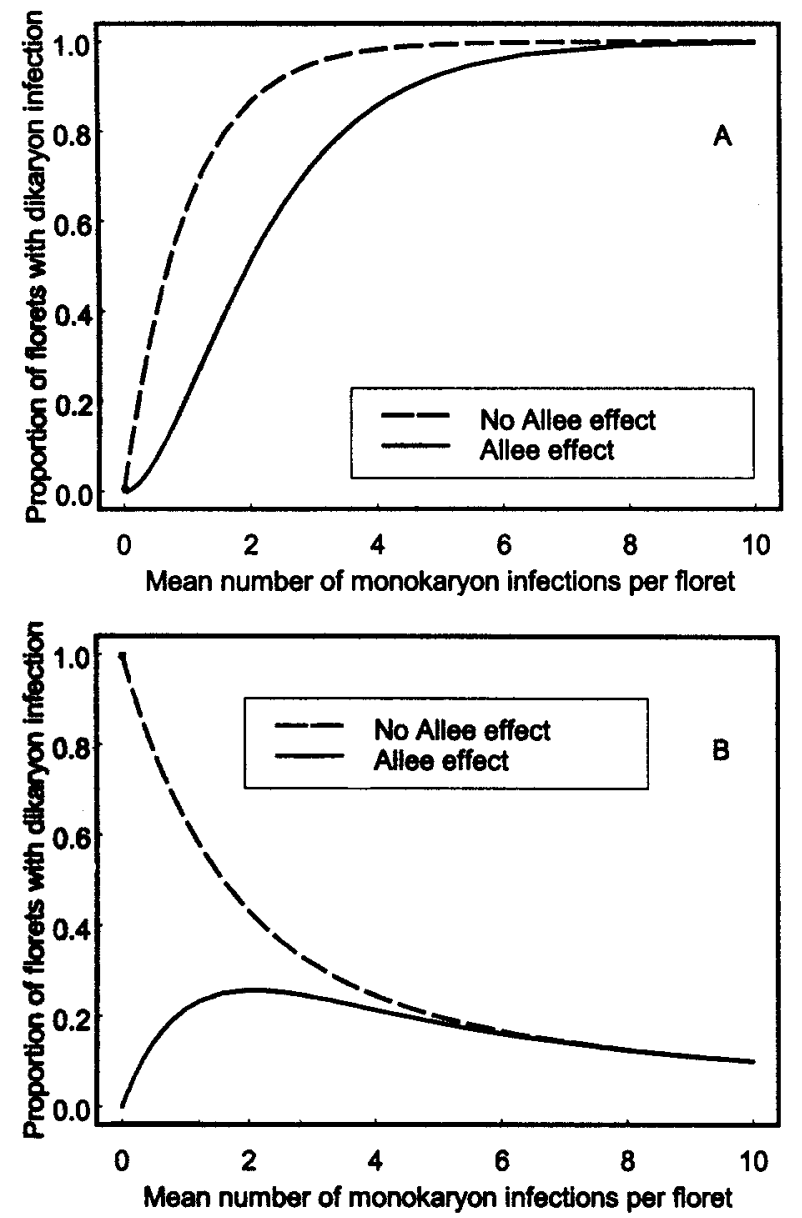

Fig. 1. Dikaryon infection frequency as a function of the mean number of monokaryon infections of Tilletia indica per wheat floret. The solid line indicates the result for $T$. indica taking into account that successful dikaryon infection requires that at least two sporidia of different mating types encounter each other within a floret (equation $3, n=4$ ). The dotted line indicates the analogous result for an organism for which a single propagule can successfully infect (equation 2, $n=1$ ). A, Frequency expressed as the proportion of florets with dikaryon infection. B, Frequency expressed as the number of dikaryon infections per monokaryon infection. This is the value of $r_{4 a}$ (Table 1 ), varying as a function of the number of monokaryon infections. 
population size at the density-dependent stage, but late season reproductive rates also contribute to determining the position of these thresholds.

These regions represent the predicted outcome based on our model and parameterization. The threshold number of teliospores would need to be lowered accordingly if the goal were to construct it such that, say, there would be $95 \%$ confidence that no dikaryon infection occurs or $95 \%$ confidence that a net loss in teliospores will result.
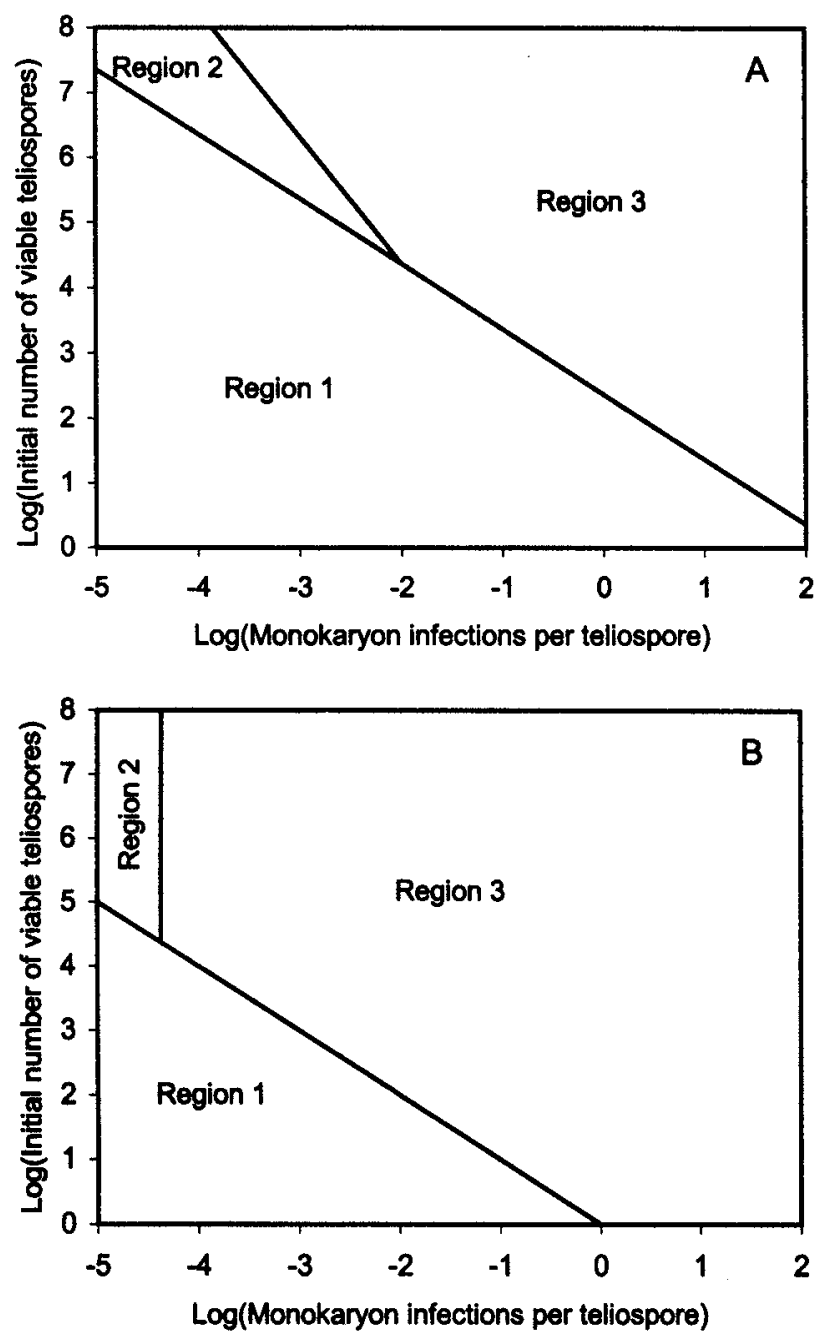

Fig. 2. Predicted outcomes for a population of Tilletia indica as a function of both the early season reproductive rate (number of monokaryon infections per teliospore, $r_{1} r_{2} r_{3}$ ) and the initial number of viable teliospores. The first measure of success is whether at least one dikaryon infection is predicted (equation 8). Region 1 indicates the parameter combinations for which less than one dikaryon infection is predicted. For lower early season reproductive rates, dikaryon infection becomes less likely. The second measure of success is whether a dikaryon infection and a net gain in the number of teliospores are predicted over the course of the season (equation 9). Region 2 indicates parameter combinations for which infection is predicted but for which there is still a net loss in teliospores. Region 3 indicates parameter combinations for which infection and a net gain in teliospores are predicted. This never occurs for lower early season reproductive rates. In this example, the late season reproductive rate $r_{4 b} r_{5} r_{6}=10,000$ (Table 1), the total number of florets is 20,000, and the proportion of viable teliospores that germinate $\left(r_{1 a} r_{1 b}\right)$ is 0.3 . A, Taking into account that secondary sporidia of $T$. indica must encounter another individual of a different mating type, there is an Allee effect and a correspondingly higher number of initial teliospores are needed to produce dikaryon infection. B, If each secondary sporidium were capable of producing a dikaryon infection, the threshold for both successful infection and net gain in teliospores would be lower.
Demographic model over multiple growing seasons. When considering population changes for $T$. indica over years, the presence of dormant soilborne teliospores must be taken into account. The number of teliospores that did not germinate in season $t$ but did survive is $\left(1-r_{1 a} r_{1 b}\right) r_{6} T_{t}$. This can be combined with equation 9 to give

$$
\begin{aligned}
T_{t+1}=r_{4 b} & r_{5} r_{6} H\left(1-\exp \left(-r_{1} r_{2} r_{3} T_{t} / H\right)-n \exp \left[-(n-1) r_{1} r_{2} r_{3} T_{t} /(H n)\right]\right. \\
\times & \left.\times\left\{1-\exp \left[-r_{1} r_{2} r_{3} T_{t} /(H n)\right]\right\}\right)+\left(1-r_{1 a} r_{1 b}\right) r_{6} T_{t}
\end{aligned}
$$

To explore the effects of environmental stochasticity, we also incorporated differences in the reproductive rates from year to year. Different reproductive rates will result in different thresholds required for a net gain in teliospore populations (Fig. 2).

Sustainability of populations of $\boldsymbol{T}$. indica. Although $T$. indica is constrained by the Allee effect at low population levels, it has the advantage of maintaining a teliospore bank to enhance its ability to reproduce when conducive years occur. Thus, even if the first year after the introduction of teliospores does not allow for reproduction, there are still possibilities in the following years (Fig. 3), though the Allee effect still limits reproduction. And at low population levels, the increase in population during a more conducive year may not be adequate to establish the population. The interval between conducive years will be important in determining whether populations of $T$. indica can persist above the threshold for net teliospore gain (Fig. 2). Figure 3 illustrates predicted population changes for one parameterization. When a conducive year, in terms of the early season reproductive rate $\left(r_{1} r_{2} r_{3}=1\right)$, occurs every 3 years, $T$. indica populations increase gradually and then more rapidly to reach levels at which there is little difference between results predicted with and without an Allee effect (Fig. 3A). When a conducive year $\left(r_{1} r_{2} r_{3}=1\right)$ occurs only every 4 years, $T$. indica populations briefly increase but then decrease because the population level falls too low to take advantage of the conducive years (Fig. 3B).

\section{DISCUSSION}

Using a simple population model, we have demonstrated how the density-dependent reproduction of $T$. indica will reduce its invasive potential. While any small population has a greater risk of extinction due to stochastic demographic events $(22,25,26,48)$, an Allee effect functions to further reduce the probability of establishment or population growth. When new populations might be initiated by airborne secondary sporidia, the likelihood of infection will decrease disproportionately because the density of sporidia decreases at greater distances from the inoculum source (Fig. 1). When teliospores may initiate a new population, the Allee effect will increase the initial population necessary for establishment by orders of magnitude (Fig. 2). Determining where this threshold lies for any given location will be challenging because the threshold shifts with the reproductive rates of the pathogen, which are in turn a potentially complicated function of weather and other variables that may vary greatly from year to year (Table 1). The intervals between conducive years will be important because declines in population size between these years may drive the population below levels needed for effective reproduction (Fig. 3).

If the level of partial resistance to Karnal bunt in wheat plants is increased, this could produce benefits both through overall lower disease levels and through the possibility of pushing $T$. indica populations below the threshold population size necessary for populations to be maintained. For example, if resistance deployment or fungicide use were to change the number of monokaryon infections per teliospore from 1 to 0.01 , this could have an important effect on the potential for invasions because the boundary between regions with predicted loss and the region with a predicted gain in teliospores could be increased by 2 orders of magnitude 
(Fig. 2). Sources of partial resistance to Karnal bunt are available and are being incorporated into advanced lines $(17,20)$. Several foliar fungicides also give fair to good control (17). In a new invasion, resistance that acts through reducing the probability of monokaryon infection $\left(r_{3 b}\right)$ could be more useful than resistance that acts through reducing the success of dikaryon formation $\left(r_{4 b}\right)$ because the former occurs before the density-dependent step of encounter between sporidia of different mating types. Pubescence on wheat heads in some cultivars has been proposed as one mechanism for resistance (43) and would act at this earlier stage.

Although teliospore dormancy will have no immediate benefit for the establishment of $\mathrm{T}$. indica in a new area, weather variables are important drivers for Karnal bunt epidemics $(3,17,27)$ and the potential for dormant teliospores to germinate later is likely an important factor for maintenance of a $\mathrm{T}$. indica population in a variable environment (14,31). If an environment is typically conducive to maintaining the population above the necessary threshold for persistence, a single nonconducive year will not eliminate the population (Fig. 3). However, if an environment is rarely sufficiently conducive to maintain the population above the threshold, the small percentage of teliospores remaining dormant until an unusually conducive year might not be enough to maintain the population. The possibility does exist that an area with a declining population in a nonconducive environment could still act as an inoculum source for another area with a more conducive environment. More information is needed about the dynamics of teliospore survival in soils.

Lewis and Kareiva (32) modeled the implications of an Allee effect for invasive species. They illustrate how the shape and pattern of an invasive front can influence the probability of invasion. For example, if secondary sporidia of $T$. indica introduced to a new area are distributed evenly, the chance that the Allee effect will be important is greater than if prevailing winds result in movement of more concentrated numbers of spores into a smaller area. The spatial extent of an invasion is also important because the chance that there will be at least some encounters between secondary sporidia of different mating types is cumulative over the area. A pathogen population at densities near or below the threshold for net teliospore gain will be maintained longer if that density is present over a larger area. For example, the lower boundary in Figure 2 would shift downward if the same concentration of monokaryon infections were present over a greater spatial extent and thus a greater number of florets.

An important assumption of our model is that secondary sporidia are distributed randomly and independently on the florets. Because allantoid secondary sporidia are individually forcibly discharged, it seems likely that they arrive at florets more or less independently. Most researchers who have developed life cycle diagrams for $T$. indica have depicted aerial deposition of secondary sporidia on florets during or after spike emergence $(4,10,28$, 41,51). However, Nagarajan et al. (35) hypothesized that floral infections may also take place inside the boot by secondary sporidia washed down by rain or dew after being deposited on the flag leaf. There is some evidence for this hypothesis (30), but the significance of this pathway is still unclear. The distribution of initial infection sites in naturally infected spikes has been observed to be sparse and apparently random $(9,17,38)$, which is consistent with a random distribution of secondary sporidia.

Although the assumption of the random and independent distribution of secondary sporidia is probably a reasonable approximation in most cases, there may be cases where epiphytic growth leads to aggregation of secondary sporidia. For example, a single wind-dispersed secondary sporidium has the potential to produce a large epiphytic population of secondary sporidia under very conducive conditions, though this population will be of a single mating type. For such a scenario, our model might be modified to consider the rate at which aggregates of a single mating type come in contact and so are capable of dikaryon formation. In this case, an Allee effect analogous to the one we have described would be experienced at a larger spatial scale when aggregates are infrequent enough that availability of an aggregate of another mating type becomes limiting. More information about epiphytic growth and the distribution of sporidia on florets and spikes would be of great benefit in formulating a more accurate assessment of the risk of invasion by this pathogen.

The life cycles of many plant pathogens or their vectors feature sexual recombination between scattered individuals and therefore could generate an Allee effect. For example, an Allee effect has been described for the insect vector of the pinewood nematode, causal agent of pine wilt $(50,54)$. The importance of an Allee effect for pathogens will be greater if (i) strains are heterothallic, (ii) the sexual portion of the life cycle is obligate, (iii) potential mates are independently dispersed, (iv) the population density is typically low, and (v) infections are localized rather than systemic.
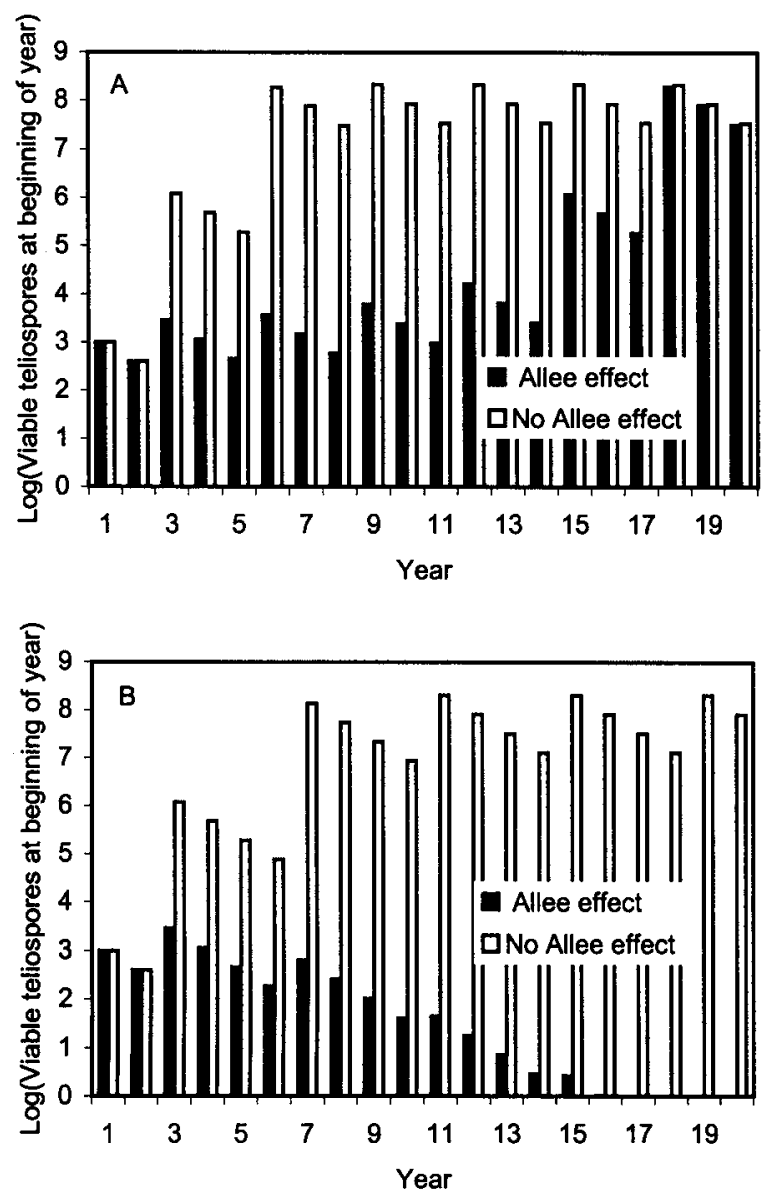

Fig. 3. The number of teliospores of Tilletia indica in a spore bank over time. In both examples, the starting population size of teliospores is 1,000 among 20,000 florets. For this illustration, we assume that each year the proportion of teliospores that germinate is $r_{1 a} r_{1 b}=0.3$ (Table 1), the proportion that die or are removed is $1-r_{6}=0.3$, and the other teliospores remain dormant until the following season. The number of surviving teliospores per infected floret, the product of the late season reproductive parameters is $r_{4 b} r_{5} r_{6}=10,000$. The value of the product of rate parameters $r_{1} r_{2} r_{3}$ varies from one season to another, as a function of weather variables or field management. The shaded bars indicate the results for a population taking into account that $T$. indica requires that at least two sporidia of different mating types encounter each other to establish a monokaryon infection in a floret (equation 11). The empty bars indicate the results for a population without that requirement so that each propagule has the potential to produce an infection. A, In this example, a conducive year, in terms of having the early season parameters $r_{1} r_{2} r_{3}=1$, occurs every 3 years beginning with the second year; for other years, $r_{1} r_{2} r_{3}=0 . \mathbf{B}$, In this example a conducive year $\left(r_{1} r_{2} r_{3}=1\right)$ occurs every 4 years. 
The smuts (Ustilaginales) include several species that would appear to possess these characteristics, including $T$. barclayana (11), $T$. horrida (52), and T. walkeri (5), in addition to T. indica $(11,12)$.

Many fungi have apparently avoided an Allee effect through reliance on asexual reproductive cycles or through modifications in the sexual cycle. Several sexual cycle variations are found in the Ustilaginales that appear to mitigate the Allee effect. First, pairs of compatible primary sporidia on the promycelium may immediately fuse and produce self-fertile, dikaryotic secondary sporidia (e.g., T. laevis $[11,41])$. Second, the promycelium may produce nonfusing, dikaryotic primary sporidia, which then produce selffertile, dikaryotic secondary sporidia (e.g., T. aegopogonis, termed homo-heterothallic by Durán [11]). Third, the dispersal propagule may be diploid teliospores that germinate and produce dikaryotic infectious hyphae directly without producing any sporidia (e.g., Ustilago tritici [41]). Under conditions when an Allee effect is important, there may be strong selection for new mutants that allow dispersal of self-fertile propagules. Fourth, multiple mating types increase the probability of encountering a compatible mate.

Asexual reproduction is an important mechanism through which $T$. indica compensates for the Allee effect because it has the potential to produce great numbers of primary and secondary sporidia $(2,21,35)$ (Table 1$)$. Thus, in a highly conducive environment, the reproductive plasticity of $T$. indica may allow it to maintain a population density high enough to experience the benefits of sexual recombination without reduced reproductive potential. Another mechanism through which $T$. indica may counterbalance the Allee effect to some extent is through dispersal of intact bunted wheat kernels so that teliospores tend to be distributed together and thus produce more concentrated populations of secondary sporidia.

The size of the Allee effect for a given environment could be estimated by constructing an experiment corresponding to Figure 1B. Florets could be spray-inoculated with a range of concentrations of secondary sporidia to determine the rate of dikaryon infection for each concentration. The extent to which the number of dikaryon infections per secondary sporidium decreases at lower inoculum levels would indicate the degree to which reproduction is density dependent in that environment. Challenges for such an experiment would be to include enough concentrations to detect trends and to include replication adequate to obtain good estimates of infection rates at the lowest concentrations. As more information about the reproductive potential of $T$. indica and its response to weather variables does become available, consideration of the Allee effect can be used to improve risk assessments $(36,46,47)$ and to inform efforts to manage the fungus.

\section{ACKNOWLEDGMENTS}

This material is based upon work supported by the National Science Foundation under Grant DEB-0130692, by NSF Grant EPS-9874732 with matching support from the State of Kansas, and by Regional Research Funds from North Central Project NC-125. This is Kansas State Experiment Station Contribution No. 02-242-J. We thank W. W. Bockus, M. Bonde, C. M. Cox, G. Fuentes-Dávila, B. J. Goates, J. C. Nelson, and Phytopathology reviewers for comments that improved this manuscript.

\section{LITERATURE CITED}

1. Babadoost, M. 2000. Comments on the zero-tolerance quarantine of Karnal bunt of wheat. Plant Dis. 84:711-712.

2. Bains, S. S., and Dhaliwal, H. S. 1989. Release of secondary sporidia of Neovossia indica from inoculated wheat spikes. Plant Soil 115:83-87.

3. Baker, R. H. A., Sansford, C. E., Jarvis, C. H., Cannon, R. J. C., Macleod, A., and Walters, K. F. A. 2000. The role of climatic mapping in predicting the potential geographic distribution of non-indigenous pests under current and future climates. Agric. Ecosyst. Environ. 82:57-71.

4. Bonde, M. R., Peterson, G. L., Schaad, N. W., and Smilanick, J. L. 1997. Karnal bunt of wheat. Plant Dis. 81:1370-1377.

5. Castlebury, L. A., and Carris, L. M. 1999. Tilletia walkeri, a new species on Lolium multiflorum and L. perenne. Mycologia 91:121-131.
6. Crous, P. W., van Jaarsveld, A. B., Castlebury, L. A., Carris, L. M., Frederick, R. D., and Pretorius, Z. A. 2001. Karnal bunt of wheat newly reported from the African continent. Plant Dis. 85:561.

7. Cruickshank, I., Gurney, W. S. C., and Veitch, A. R. 1999. The characteristics of epidemics and invasions with thresholds. Theor. Popul. Biol. 56:279-292.

8. Dhaliwal, H. S., Navarrete-Maya, R., and Valdez, C. J. 1989. Scanning electron microscope studies of penetration mechanism of Tilletia indica in wheat spikes. Rev. Mex. Fitopatol. 7:150-155.

9. Dhaliwal, H. S., Randhawa, A. S., Chand, K., and Singh, D. 1983. Primary infection and further development of Karnal bunt of wheat. Indian J. Agric. Sci. 53:239-244.

10. Dhaliwal, H. S., and Singh, D. V. 1988. Up-to-date life cycle of Neovossia indica (Mitra) Mundkur. Curr. Sci. 57:675-677

11. Durán, R. 1987. Ustilaginales of Mexico. Washington State University, Pullman.

12. Durán, R., and Cromarty, R. 1977. Tilletia indica: A heterothallic wheat bunt fungus with multiple alleles controlling incompatibility. Phytopathology 67:812-815.

13. Evans, M., Hastings, N., and Peacock, B. 1993. Statistical Distributions. John Wiley \& Sons, New York.

14. Fenner, M. 1985. Seed Ecology. Chapman \& Hall, London.

15. Fernando, W. G. D., Paulitz, T. C., Seaman, W. L., Dutilleul, P., and Miller, J. D. 1997. Head blight gradients caused by Gibberella zeae from area sources of inoculum in wheat field plots. Phytopathology 87:414421.

16. Fuentes-Dávila, G. 1989. Studies on the incompatibility system of Tilletia indica. Rev. Mex. Fitopatol. 7:201-207.

17. Fuentes-Dávila, G. 1996. Karnal bunt. Pages 26-32 in: Bunt and Smut Diseases of Wheat: Concepts and Methods of Disease Management. R. D. Wilcoxson and E. E. Saari, eds. CIMMYT, Mexico, D.F.

18. Fuentes-Dávila, G. 1998. Karnal bunt of wheat. Pages 69-81 in: Bunts and Smuts of Wheat: An International Symposium. V. S. Malik and D. E. Mathre, eds. North American Plant Protection Organization, Ottawa.

19. Fuentes-Dávila, G., and Durán, R. 1986. Tilletia indica: Cytology and teliospore formation in vitro and in immature kernels. Can. J. Bot. 64: 1712-1719.

20. Fuentes-Dávila, G., and Rajaram, S. 1994. Sources of resistance to Tilletia indica in wheat. Crop Prot. 13:20-24.

21. Goates, B. J. 1988. Histology of infection of wheat by Tilletia indica, the Karnal bunt pathogen. Phytopathology 78:1434-1441.

22. Goates, B. J., and Peterson, G. L. 1999. Relationship between soilborne and seedborne inoculum density and the incidence of dwarf bunt of wheat. Plant Dis. 83:819-824.

23. Grevstad, F. S. 1999. Factors influencing the chance of population establishment: Implications for release strategies in biocontrol. Ecol. Appl. 9:1439-1447.

24. Hackney, E. E., and McGraw, J. B. 2001. Experimental demonstration of an Allee effect in American ginseng. Conserv. Biol. 15:129-136.

25. Jeger, M. J., and van den Bosch, F. 1994. Threshold criteria for model plant disease epidemics. I. Asymptotic results. Phytopathology 84:24-27.

26. Jeger, M. J., and van den Bosch, F. 1994. Threshold criteria for model plant disease epidemics. II. Persistence and endemicity. Phytopathology 84:28-30.

27. Jhorar, O. P., Mavi, H. S., Sharma, I., Mahi, G. S., Mathauda, S. S., and Singh, G. 1992. A biometeorological model for forecasting Karnal bunt disease of wheat. Plant Dis. Res. 7:204-209.

28. Joshi, L. M., Singh, D. V., Srivastava, K. D., and Wilcoxson, R. D. 1983. Karnal bunt: A minor disease that is now a threat to wheat. Bot. Rev. 49:309-330.

29. Kot, M., Lewis, M. A., and Van den Driessche, P. 1996. Dispersal data and the spread of invading organisms. Ecology 77:2027-2042.

30. Kumar, J., and Nagarajan, S. 1998. Role of flag leaf and spike emergence stage on the incidence of Karnal bunt in wheat. Plant Dis. 82:13681370.

31. Leck, M. A., Parker, V. T., and Simpson, R. L., eds. 1989. Ecology of Soil Seed Banks. Academic Press, San Diego, CA.

32. Lewis, M. A., and Kareiva, P. 1993. Allee dynamics and the spread of invading organisms. Theor. Pop. Biol. 42:141-158.

33. Liermann, M., and Hilborn, R. 2001. Depensation: Evidence, models and implications. Fish Fish. Ser. 2:33-58.

34. Mitra, M. 1931. A new bunt disease of wheat in India. Ann. Appl. Biol. $18: 178-179$

35. Nagarajan, S., Aujula, S. S., Nanda, G. S., Sharma, I., Goel, L. B., Kumar, J., and Singh, D. V. 1997. Karnal bunt (Tilletia indica) of wheat-A review. Rev. Plant Pathol. 76:1207-1214.

36. North American Plant Protection Organization. 2001. An epidemiological approach to assessing the risk of establishment of Karnal bunt, Tilletia indica Mitra, in North America. Online publication no. KB- 
Aug25-01.

37. Paulitz, T. C., Dutilleul, P., Yamasaki, S. H., Fernando, W. G. D., and Seaman, W. L. 1999. A generalized two-dimensional Gaussian model of disease foci of head blight of wheat caused by Gibberella zeae. Phytopathology 89:74-83.

38. Rattan, G. S., and Aujla, S. S. 1991. Distribution of infection in Karnal bunt infected wheat spike. Ann. Biol. 7:225-228.

39. Royer, M. H., and Rytter, J. 1986. Relationship between kernel infection and spike infection of wheat by Tilletia indica, causal agent of Karnal bunt. Plant Dis. 70:225-228.

40. Royer, M. H., and Rytter, J. 1988. Comparison of host ranges of Tilletia indica and T. barclayana. Plant Dis. 72:133-136.

41. Saari, E. E., Mamluk, O. F., and Burnett, P. A. 1996. Bunts and smuts of wheat. Pages 1-11 in: Bunt and Smut Diseases of Wheat: Concepts and Methods of Disease Management. R. D. Wilcoxson and E. E. Saari, eds. CIMMYT, Mexico, D.F.

42. Saether, B. E., Ringsby, T. H., and Roskaft, E. 1996. Life history variation, population processes and priorities in species conservation: Towards a reunion of research paradigms. Oikos 77:217-226.

43. Salazar, H. F. J., Osada, K. S., Gilchrist, S. L., and Fuentes-Dávila, G. 1990. Evaluation of resistance in six wheat (Triticum vulgare L.) genotypes to partial bunt caused by the fungus Tilletia indica. Rev. Mex. Fitopatol. 8:145-152.

44. Singh, D. V., and Dhaliwal, H. S. 1988. Establishment and spread of Karnal bunt in wheat spike. Seed Res. 16:200-205.
45. Smilanick, J. L., Prescott, J. M., Hoffman, J. A., Secrest, L. R., and Weise, K. 1989. Environmental effects on survival and growth of secondary sporidia and teliospores of Tilletia indica. Crop Prot. 8:86-90.

46. Smiley, R. W. 1997. Risk assessment for Karnal bunt occurrence in the Pacific Northwest. Plant Dis. 81:689-692.

47. Stansbury, C. D., McKirdy, S. J., Diggle, A. J., and Riley, I. T. 2002. Modeling the risk of entry, establishment, spread, containment, and economic impact of Tilletia indica, the cause of Karnal bunt of wheat, using an Australian context. Phytopathology 92:321-331.

48. Stephan, T., and Wissel, C. 1994. Stochastic extinction models discrete in time. Ecol. Model. 75/76:183-192.

49. Stephens, P. A., Sutherland, W. J., and Freckleton, R. P. 1999. What is the Allee effect? Oikos 87:185-190.

50. Takasu, F., Yamamoto, N., Kawasaki, K., Togashi, K., and Shigesada, N. 2000. Modeling the range expansion of an introduced tree disease. Biol. Invasions 2:141-150.

51. Warham, E. J. 1986. Karnal bunt disease of wheat: A literature review. Trop. Pest Manag. 32:229-242.

52. Whitney, N. G. 1989. Taxonomy of the fungus causing kernel smut of rice. Mycologia 81:468-471.

53. Ykema, R. E., Floyd, J. P., Palm, M. E., and Peterson, G. L. 1996. First report of Karnal bunt of wheat in the United States. Plant Dis. 80:1207.

54. Yoshimura, A., Kawasaki, K., Takasu, F., Togashi, K., Futai, K., and Shigesada, N. 1999. Modeling the spread of pine wilt disease caused by nematodes with pine sawyers as vector. Ecology 80:1691-1702.

\section{Erratum}

\section{Vol. 92, No. 11, 2002}

In the manuscript entitled "An Allee Effect Reduces the Invasive Potential of Tilletia indica" by K. A. Garrett and R. L. Bowden (Phytopathology 92:1152-1159), there are three corrections that should be noted. The entry in the second column of Table 1, corresponding to $r_{1 c}$, should read, "Number of primary sporidia produced per teliospore on the soil surface that germinates." The vertical axis label in Figure 1B should read, "Dikaryon infections per monokaryon infection." The fifth complete sentence in the legend of Figure 3 should read, "The shaded bars indicate the results for a population taking into account that reproduction in $T$. indica requires that at least two sporidia of different mating types encounter each other to establish a dikaryon infection in a floret (equation 11)." 